\title{
THE STIMULATION OF PREMATURE RIPENING BY CHEMICAL MEANS.
}

\author{
BY A. E. VINSON \\ Received December 3, roog.
}

Artificial ripening of persimmons, dates and other fruits has been practiced for many years, but some particular substance has always been deemed essential, such as the empty sake barrel for persimmons or cloths moistened with vinegar for dates. Analogous to this and probably due to similar biochemical phenomena is the forcing of buds to open prematurely by what is supposed to be anesthetization, or by the application of heat as shown by Molisch. ${ }^{1}$ The premature sprouting of newly formed tubers by stimulation with divers chemicals, which has been accomplished recently by $\mathrm{McCa}$ (lum, ${ }^{2}$ belongs to this same general class of phenomena. Many plants ${ }^{3}$ which contain certain glucosides and emulsin show an abnormally large exhalation of hydrocyanic acid or other substances after treatment with anesthetics and other poisonous vapors or by freezing, and this is accompanied by marked plasmolysis.

For a critical study of the influence of chemicals in initiating the premature ripening of fruits, a tree of particularly well adapted seedling dates was available. The fruits were light yellow when unripe and indicated their start to ripen by the appearance of a well-marked translucency, which increased and darkened until they became a deep chocolatebrown. The effect of over one hundred separate substances was studied on this material, either by exposing the fruits to the vapor of the volatile ones or by soaking them in solutions of the nonvolatile compounds.

The first results ${ }^{4}$ seemed to indicate that the effect was dependent on chemical structure, since certain groups gave very marked results while others did not. Acetic acid and acetic ether were equally efficient, and five per cent. solutions of sodium or potassium acetate also gave good results. Aniline acetate vapor acted slowly but perfectly. Solutions of both benzoic and salicylic acids acted very promptly and completely. Oxalic acid gave marked results but malonic and succinic acids appeared to act much better. Citric, tartaric, and malic acids gave only imperfect results. In the first trials ordinary ether, chloroform and acetone failed, but it was found later that dates responded only to nearly saturated vapors of these reagents. Many substances which are not easily volatile acted quickly by direct contact but very slowly by their vapors. In general the more volatile the substance the quicker it acted; thus benzene and toluene acted very completely over

1 "Das Warmbad als Mittel zum Treiben der Pflanzen," Jena, I909.

${ }^{2}$ Unpublished work, Arizona Agr. Exp. Station.

'Mirande, Compt. rend., I49, I40; Guignard, Compt. rend., I49, 91.

Science, 30, 604 (I909). 
night, but xylene, in the same time, affected only the bottom of the column of fruit above it, the effect traveling slowly upward. Oil of eucalyptus acted quite readily, while pennyroyal and cassia were very slow excepting by contact. Eugenol acted quickly by contact but its vapor was without effect even after many days' exposure. Camphor and naphthalene were not sufficiently volatile to give any result. Among the more peculiar results were those obtained with iodoform. With this substance the entire column turned uniformly, there being no difference between the fruits in actual contact and those farther away.

A detailed account of the action of the various substances used, grouped according to their efficiency, is given below:

Fruits turned uniformly throughout the column over night by saturated vapors of the following:

Ether, chloroform, acetone, gasoline, carbon disulphide, benzene, toluene, allylisosulphocyanate, ethyl and methyl alcohols (a little slow, methyl alcohol acting better), ethyl acetate, ethyl butyrate, ethyl oxalate, ethyl chloride, ethyl bromide, acetyl chloride (not in excess), ethylene chloride (very efficient), methyl dichloride (very efficient), amyl formate, amyl acetate, acetic acid, propionic acid, butyric acid and acetal.

Fruits turned uniformly over night but farther ripening did not proceed normally with saturated vapors of:

Formaldehyde, acetaldehyde, formic acid, methyl acetate and ethyl formate. Possibly some of these would have been efficient in less concentration since excess probably interfered with the action of the enzymes.

Fruits ripened by contact over night, those above ripening in the next 24 to 48 hours:

Xylene, amyl alcohol, isobutyl alcohol, diacetic ester, benzyl chloride, benzoyl chloride, chloral, ethyl succinate, ethyl benzoate, cumene, cymene, geraniol, citral, coal oil, turpentine.

Fruits ripened by contact in the first few days; those above ripened only after prolonged exposure to vapor:

Mono-, di- and trichloroacetic acids, monobromoacetic acid, aniline acetate, pyridine, toluidine, oil of eucalyptus, benzaldehyde, hypnone, iodoform (by contact and by vapor ripening at the same time), terpineol.

Fruits ripened by contact only:

Aniline, phenolhydrazine, thymol, oil of cassia and oil of pennyroyal.

Fruits not affected:

Camphor, naphthalene, menthol, hydrochloric acid; blackened and destroyed by phenol; damaged but not ripened by chloral hydrate and sulphur dioxide.

Ethyl and amyl nitrite penetrate very rapidly and react chemically with the content of the tannin cells, causing it to precipitate and form 
insoluble tannin grains at once. ${ }^{1}$ Due to the darkening of the fruit the effect on ripening other than the removal of astringency is difficult to follow. In smaller quantities it appears to stimulate the other ripening phenomena and very palatable fruits can be prepared by the use of nitrous esters. Ammonia in small quantities causes a general reddening of the fruits with shrinking at the basal end. The general ripening phenomena follow fairly well and after some clays the fruits are edible.

The stimulation due to solutions was not so easily traced as that due to vapors. The first effect usually manifested itself by the appearance of translucent spots instead of the fruit turning as a whole. Many substances caused the skin to crack and curl badly, sometimes accompanied by ripening, sometimes not. Saturated solutions of benzoic and salicylic acids over night produced first effects very similar to those produced by vapors, while malonic, succinic and lactic acids in three per cent. solutions and the acid amides were almost equally efficient.

The following substances in solution caused all or nearly all the treated fruits to ripen:

Benzoic acid, salicylic acid, sodium benzoate, sodium salicylate, sodium acetate, potassium acetate, oxalic, malonic and succinic acids, lactic acid, acetamide, formamide, hippuric acid, cinnamic acid, hydroxylamine hydrochloride; hydrazine hydrochloride starts the process but normal ripening does not follow.

The following substances ripen from one-half to two-thirds of the fruits treated:

Tartaric, citric and malic acids, trichloroacetic acid (one-tenth per cent. solution), ammonium acetate, manganese sulphate and aniline acetate.

The following gave doubtful or negative results:

Potassium sulphate, manganese chloride, sulphanilic acid, acetanilide, phenacetine, protocatechuic acid, pyrogallol, orcinol, resorcinol and vanillin.

From the diversity of these reagents it is evident that the effects observed cannot be due to any particular chemical structure, nor do many of them react chemically with any known constituent of the date. Furthermore, after treatment over night with acetic acid vapor, an appreciable reaction for invertase could be obtained in the glycerol extract although a marked astringency was still present. From these facts and previous work on the intracellular invertase of the date, ${ }^{2}$ including some recent observations $^{3}$ on the chemical organization of the green fruit while it retained its physical integrity; it was concluded that this apparent stimulation of ripening depended solely on the killing of the protoplasm. In broad terms any substance which will penetrate the cuticle and kill or

${ }^{1}$ Bot. Gaz. The work is now in process of publication.

2 This Journal, 30, 1005 (igo8).

s Plant World, Jan., Igro. 
stimulate the protoplasm, thereby releasing the previously insoluble intracellular enzymes without rendering them inactive, will bring about ripening, provided the fruits have reached a certain necessary degree of maturity.

The validity of this theory was tested by an experiment devised to accomplish the same results by purely physical means. Sprays of dates were heated in water for five and ten minutes at every five degrees between 60 and $95^{\circ}$. Below $60^{\circ}$ they lost their astringency but remained very light colored like untreated fruits. Above $60^{\circ}$ the color became darker, reaching a maximum at about $75^{\circ}$. At $80^{\circ}$ the general aspect of the sprays was more uneven, and even the darkest individuals remained exceedingly astringent and very sweet. Above $80^{\circ}$ the color of the entire sprays became very light, matching exactly the more immature individuals heated below $60^{\circ}$. Unlike the results obtained by treatment with chemicals, the effects of heat stimulation become plainly manifest only after the lapse of several days. The results, however, show clearly that if dates are heated sufficiently to destroy protoplasm but not enzymes, the ripening phenomena will follow quite completely, while at higher temperatures all ripening ceases.

Apsit and Gain ${ }^{1}$ have shown that seeds lose their viability when subjected to anesthetics for a considerable length of time but their diastase and peroxydase remain active. In this case as in others, anesthesia in the accepted meaning of the word has nothing to do with the effects produced. The only connection is that certain substances, among many others, which kill or stimulate the protoplasm happen to produce anesthesia in animals.

The more immature fruits heated to $70^{\circ}$ for ten minutes or longer darkened nicely but remained astringent. At higher temperatures even the more mature fruits remained permanently astringent while untreated immature fruits gradually lost their astringency. These facts can be explained only as the direct or indirect action of some specific enzyme that is destroyed at about $70^{\circ}$. Hydrazine hydrochloride interfered with the general trend of ripening but the astringency disappeared.

Commercially, many varieties of dates may be ripened rapidly after they have reached a certain degree of maturity. Before that time they do not contain sufficient dry matter to make a palatable fruit. Many varieties so ripened are fully equal to the natural product. This may be accomplished by exposing them to the vapors of a great many substances, but only a few are commercially practical, due to the bad flavors which most of them impart. Fruit of good flavor was obtained by treatment with the vapors of acetic and propionic acids, ethyl chloride, ethyl bromide, ethylene chloride, methylene chloride and chloroform; and with

${ }^{1}$ Compt. rend., I49, 58 (1909). 
solutions of lactic, benzoic and salicylic acids and some other substances of more or less poisonous nature. Gasoline, benzene, esters of organic acids, ordinary ether, acetone, volatile oils and most other substances leave permanent disagreeable flavors.

Deglet Noor dates do not yield satisfactorily to these methods but can be made palatable and, if sufficiently mature, will yield fruit of fair quality when subjected to the judicious use of ethyl nitrite vapor. A small amount of this reagent $\left(\frac{1}{4}\right.$ to $\frac{1}{2} \mathrm{cc}$. of 20 per cent. solution for every $1000 \mathrm{cc}$. of space enclose ${ }^{-1}$ will finally render the tannin insoluble without discoloring the date badly or imparting any noticeable flavor.

It is anticipated that the application of these methods will prevent much of the enormous loss from souring which is experienced at present during unfavorable weather. Artificially ripened dates do not sour so readily as the fruit ripened on the tree and remain much freer from insects.

ARIZONA AGR. FXP. Station,

TECSON, ARIZONA.

\section{THE ACIDS OF THE PHENYLPROPIOLIC SERIES AND THEIR CONDENSATION TO NAPHTHALENE DERIVATIVES. ${ }^{1}$}

BY JOHN E. BUCHER.

Received December 9, 1909 .

In an investigation of the action of acetic anhydride on acids of the acetylene series in I895, Michael and Bucher ${ }^{2}$ obtained the anhydride of a new acid from phenylpropiolic acid. Three years later, ${ }^{2}$ after a thorough study of the compound, they proved it to be the anhydride of I-phenyl-2,3-naphthalenedicarboxylic acid. It was found to have the composition corresponding to the formula $\mathrm{C}_{18} \mathrm{H}_{10} \mathrm{O}_{3}$ and a molecular weight of 274 .

This corresponds to the composition of a phenylpropiolic anhydride $\left(\mathrm{C}_{6} \mathrm{H}_{5} \cdot \mathrm{C}=\mathrm{C} . \mathrm{CO}\right)_{2} \mathrm{O}$, but the acid obtained from it was found to be saturated and entirely different from phenylpropiolic acid. This structural formula evidently does not represent its constitution.

It seemed probable that three molecules of the acid might have polymerized to triphenyltrimesic acid in a manner analogous to the for-

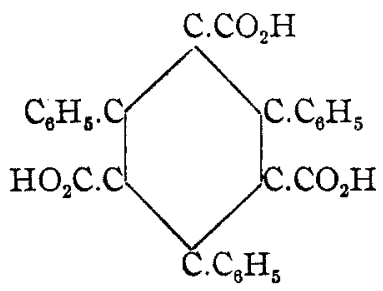

'Presented at the Second Decennial Celebration of Clark University, Worcester, Mass., September 14, 1909.

${ }^{2}$ Ber., 28, 25 I I (1895).

- Am. Chem. J., 20, 89 (1898). 